\author{
Christoph Moor • Wim Devos • Maria Guecheva \\ Judith Kobler
}

\title{
Inductively coupled plasma mass spectrometry: a versatile tool for a variety of different tasks
}

\begin{abstract}
In a laboratory that is working in many different fields, a systematic approach is needed to decide efficiently how a given analytical task should be handled. Four typical examples are presented to show how ICP-MS may be used to solve client's problems. The examples are: the identification of lead projectiles, the determination of total and leachable fractions of impurities in a polymer (PVDF), used for manufacturing components of ultrapure water distribution systems, the authentication of antique silver alloys, and the determination of rare earth elements in geological materials. These examples demonstrate not only typical challenges for the instruments and the analysts handling them, but also ways to reach a satisfactory solution within a reasonable amount of time.
\end{abstract}

\section{Introduction}

In our laboratory, we are faced daily with contract analyses for industry, authorities and research institutes, and the needs of the individual clients are usually very different. A systematic and standardized approach can help to find an effective and efficient solution for all different kinds of analytical problems. The usual steps in performing an analytical task are shown in Fig. 1. During the initial discussion with a potential client, the analyst has to "translate" the problem into a question that can be answered by a chemical analysis. Then, he has to perform a systematic evaluation of four factors that influence the decision on how to proceed in the laboratory (Fig. 2):

The market situation: Who is the client? A chemical company or a private antique dealer have different requirements for a chemical analysis. Will a given analysis have to be performed only once or many times? Is that specific field important for the laboratory or not? Is there a strong competition?

C. Moor (区) - W. Devos · M. Guecheva · J. Kobler Swiss Federal Laboratories for Materials Testimg and Research (EMPA), CH-8600 Dübendorf, Switzerland

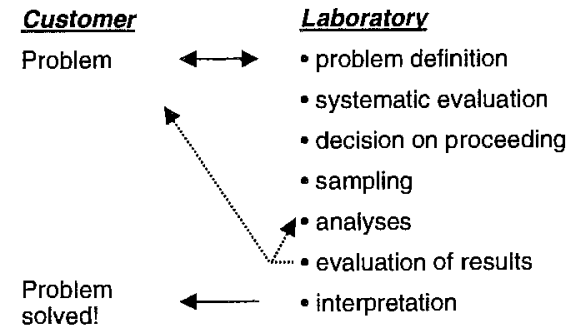

Fig. 1 Problem solving in contract analysis

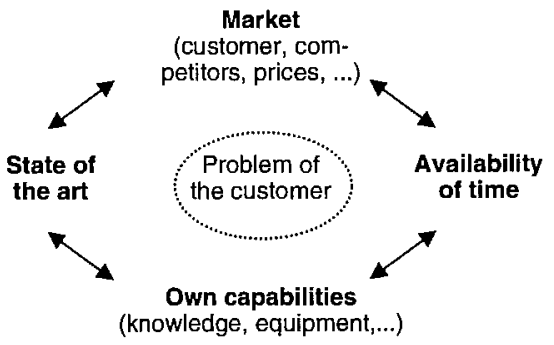

Fig. 2 Systematic evaluation of the four important factors which can influence the analysis procedure

Own capabilities: Do we have specific experience, and do we have the necessary equipment? Are the manpower and the instruments available at the moment?

The state of the art: Is there a more efficient or more sophisticated technique than that we currently use? Is this field important enough for us that we should try to move towards this state of the art?

The availability of time: Do we have to develop and validate new methods or is everything at hand? For some problems, "very urgent" means the result should be available in a couple of hours, and in this case there is no time to buy a more sophisticated spectrometer or even for a literature search.

Obviously these four factors interact with each other, and they have to be regarded from the viewpoint of the current problem to be solved. Not all factors are equally impor- 
tant for all questions, but the one we always have to know is our capability and our instrumental equipment. This is the "toolbox" with which we have to work. Not only the main instruments (inductively coupled plasma-mass spectrometry, inductively coupled plasma-emission spectrometry, atomic absorption spectrometry, X-ray fluorescence spectrometry and ion chromatography) with different sample introduction systems (nebulizers, laser ablation, electrothermal volatilization), but also sample preparation methods (sampling, digestions) or protocols such as the determination of the measurement uncertainty, the quality assurance system or the contamination control are considered as "tools". The task of the analyst is to choose the appropriate tools to solve the given problem and obtain the agreement of the client. After that decision, samples are taken and analyzed, and subsequently the results are evaluated and compared to the original problem. Depending on the results, it can happen that more measurements need to be performed, or further discussions with the client are necessary. Finally, the analyst can write the report answering the question and thus solving the client's problem.

Four examples are presented and discussed, in order to show how this approach is used in a contract laboratory. These examples also demonstrate typical ways in which an ICP-MS is used in a laboratory carrying out "non-routine testing".

\section{Experimental}

\section{Instrumentation}

An inductively coupled plasma-mass spectrometer (ELAN 6000, Perkin Elmer-Sciex) was operated under standard conditions. An ultrasonic nebulizer (U-5000, Cetac Technologies Inc.) and an electrothermal volatilization unit (HGA 600MS, Perkin Elmer) were used for some experiments. A laser sampler (Model 320, Perkin Elmer) with the original Nd:YAG laser was operated at $523 \mathrm{~nm}$ (Spectra-Physics). Several modifications were made which are described in detail elsewhere: the software controlling the laser parameters and the sample positioning [1], the autofocus system [2] and the sample cell designed for the direct ablation on large objects [3]. For the digestion of geological materials, a microwave digestion device (MLS 1200 mega, Milestone) was used. Ultra-pure water with a resistivity $>18 \mathrm{M} \Omega \times \mathrm{cm}$ was produced in a water purification system (Milli-Q gradient A10, Millipore).

\section{Procedures}

Samples from lead projectiles were taken using a pair of nippers. About $200 \mathrm{mg}$ of the material was digested on a hot plate with about $5 \mathrm{~mL}$ nitric acid. The determination of impurities by ICPMS was carried out using the semi-quantitative analysis program "Totalquant" (Perkin Elmer-Sciex). For the isotope ratio measurements, mass bias was corrected by the lead isotopic standard SRM 981 (NIST, Gaithersburg).

Granules of polyvinylidene fluoride (PVDF) were digested following an industrial standard procedure [4]. The material was washed with isopropyl alcohol, diluted $\mathrm{HNO}_{3}$, diluted $\mathrm{HCl}$, and deionized water. About $2 \mathrm{~g}$ material was placed into a platinum crucible and charred with a gas torch. The crucible with the black residue was then placed in a muffle furnace for six hours at $600^{\circ} \mathrm{C}$. Afterwards, $1 \mathrm{~mL} \mathrm{HCl}(30 \% \mathrm{~m} / \mathrm{m})$ was added and evaporated to dryness on a hot plate. The residue was re-dissolved in $0.5 \mathrm{~mL}$
$\mathrm{HNO}_{3}(65 \% \mathrm{~m} / \mathrm{m})$, transferred to a $20 \mathrm{~mL}$ flask and made up to volume with ultra-pure water. The Pt crucibles were cleaned by flaming them with a gas torch until they were red hot, rinsed in diluted nitric acid and rinsed in ultra-pure water.

Leaching tests of components were carried out following an industrial standard procedure [5]. All procedures were carried out at class 100 clean room conditions. The component was rinsed with ultra-pure water ten times for two minutes, then filled an 11th time for the test at $85^{\circ} \mathrm{C}$ for 7 days. Analytical samples were then taken for the determination of metals, non-purgable organic carbon and anions. For the 1-, 7- and 28-day leaching tests, the water was completely changed after the 1- and 7-day samples had been taken. For the ICP-MS analysis, the samples were stabilized adding 3 drops $\mathrm{HNO}_{3}(65 \% \mathrm{~m} / \mathrm{m})$ to $10 \mathrm{~mL}$ of sample. The ICP-MS determinations were performed with an ultrasonic nebulizer. The elements $\mathrm{K}, \mathrm{Ca}$ and $\mathrm{Fe}$ were determined by the cool-plasma technique [6] using a conventional cross-flow nebulizer and spray chamber.

Antique silver alloys were analyzed 1) after digestion in aqua regia, 2) by a micro-digestion in the graphite tube for ETV-ICPMS and 3) directly by laser ablation. These procedures have been described previously [3,7].

The digestion of geological materials and the determination of rare earth elements by ICP-MS were developed in collaboration with the Institute of Mineralography and Petrography (ETH Zurich) [8]. About $200 \mathrm{mg}$ of the sample was placed in a PFA microwave vessel. $4 \mathrm{~mL} \mathrm{HNO}_{3}(65 \% \mathrm{~m} / \mathrm{m})$ and $1 \mathrm{~mL} \mathrm{HF}(40 \% \mathrm{~m} / \mathrm{m})$ were added, and then a microwave digestion was carried out using a stepwise increased power $(200 \mathrm{~W}, 250 \mathrm{~W}, 300 \mathrm{~W}, 400 \mathrm{~W}$; each step for $10 \mathrm{~min}$ ). After cooling, the remaining solution was transferred to a volumetric flask (polyethylene) and made up to $100 \mathrm{~mL}$. $\mathrm{Cd}$ and Re were added as internal standards, and the determination by ICP-MS was carried out with a corrosion-resistant sample introduction system.

\section{Results and discussion}

\section{Comparison of lead projectiles of different origin}

A pistol bullet that had been fired was to be compared with five new ones of known origin. The term "compare" had to be defined: is it possible to establish a classification of the samples according to their chemical composition? This problem is known in forensic chemistry $[9,10]$, and laser ablation ICP-MS had been used successfully in this field of application $[11,12]$. It was likely that we would encounter this specific problem only once, and therefore it was easier to dissolve a fraction of the sample rather than to optimize a laser ablation procedure. A semi-quantitative analysis was done in order to have a large number of elements to search for similar composition. However, the results could not easily be interpreted, since the number of samples and the number of detectable elements was too small to apply statistical methods (Fig. 3). The determination of $\mathrm{Pb}$ isotope ratios has shown to be a useful tool for identification of $\mathrm{Pb}$ sources in forensic [10], environmental [13-17], and archaeometric studies [18, 19]. In this case, it turned out to be a very convincing and straightforward way to solve the problem, and it was easily possible to perform these measurements thanks to the initial decision to dissolve a sub-sample. The ratios ${ }^{207} \mathrm{~Pb} /{ }^{206} \mathrm{~Pb}$ and ${ }^{208} \mathrm{~Pb} /{ }^{206} \mathrm{~Pb}$ of the unknown sample showed an excellent coincidence with only one of the samples of known origin (as shown in Fig.4), whereas the four other samples formed a second group. The result answered the initial question of 
Fig. 3 Impurities in six lead bullet samples; Sample $S 1$ is the unknown sample

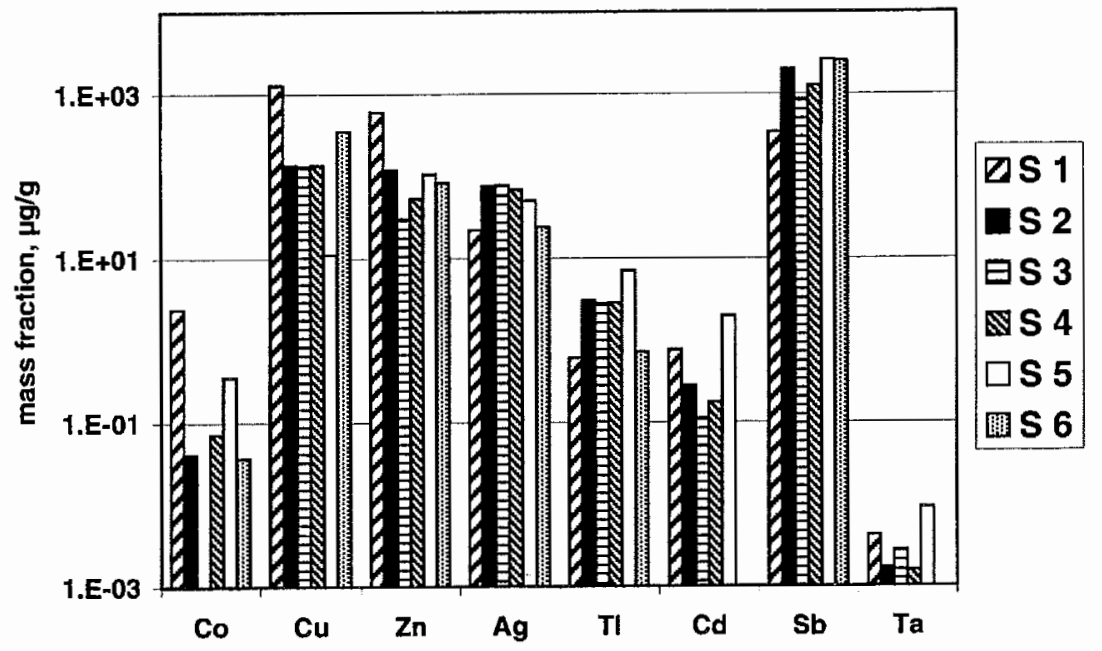

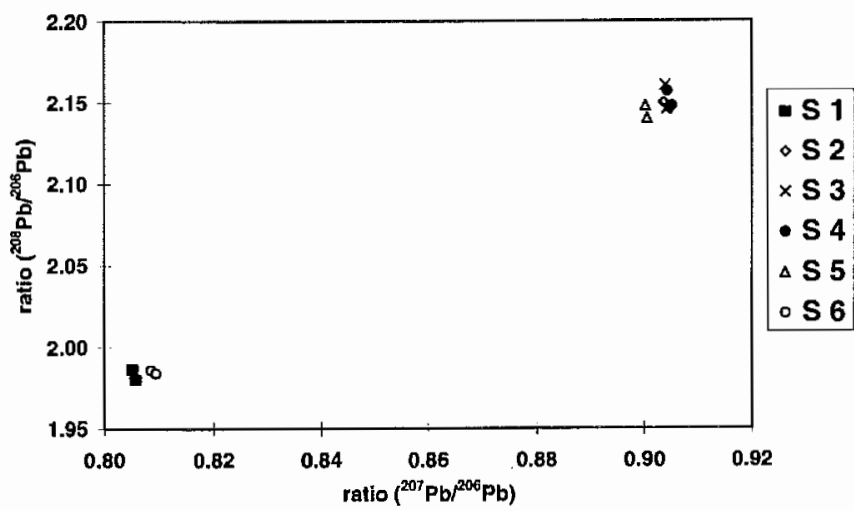

Fig. 4 Isotope ratios of ${ }^{208} \mathrm{~Pb} /{ }^{206} \mathrm{~Pb}$ vs. ${ }^{207} \mathrm{~Pb} /{ }^{206} \mathrm{~Pb}$. The confidence interval $(95 \%)$ of the measurement $(n=10)$ was below $0.3 \%$ for all samples

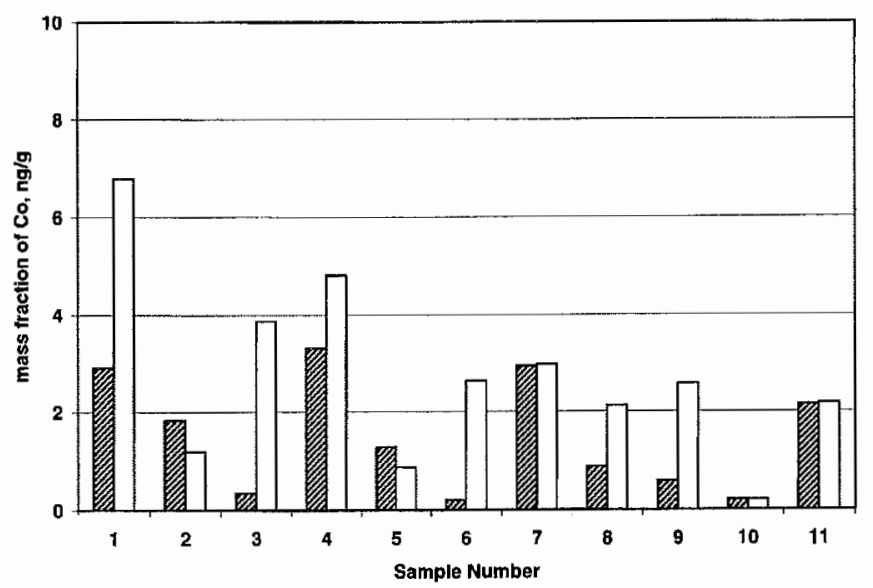

Fig. 5 Determination of Co in 11 batches of PVDF granulates. The two columns represent duplicate determinations obtained by two separate digestions. The detection limit based on the standard deviation of the procedure blanks was $0.1 \mathrm{ng} / \mathrm{g}$

the client, although neither a similar composition nor a similar isotopic pattern can unambiguously confirm that two samples stem from the same source.

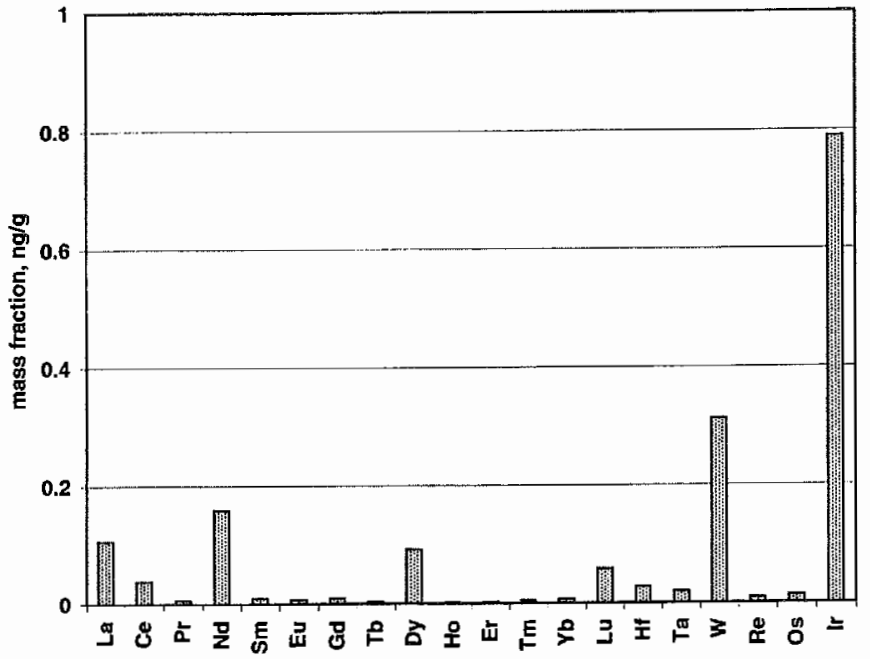

Fig.6 Memory effects from the spike solution in a procedural blank, after normal cleaning of the Pt crucible

Materials and components

for ultra-pure water distribution systems

The levels of acceptable impurities in water used in the manufacturing process of semiconductors are in the range $\mathrm{pg} / \mathrm{L}$ to $\mathrm{ng} / \mathrm{L}[20,21]$. The quality control of components for ultra-pure water distribution systems includes the determination of total and leachable metallic impurities in materials such as PVDF. These tests are used to check the specifications of a final component or to test alternative raw materials. In any case, it is important that the analysis can be reproduced at the same quality level over years.

A typical result of the total mass fraction of cobalt in different batches of PVDF is displayed in Fig. 5. Co was chosen because it was one of the few elements that was present at detectable levels in nearly all samples. The mass fraction of Co is generally around $5 \mathrm{ng} / \mathrm{g}$, but the comparison between duplicate digestions suggests that the homogeneity varies from batch to batch. Recovery rates ranged from $60 \%$ to $90 \%$ for $\mathrm{Cr}, \mathrm{Mn}, \mathrm{Fe}, \mathrm{Co}, \mathrm{Ni}$ and $\mathrm{Zn}$. For $\mathrm{Na}$, a recovery of $128 \%$ indicated a contamination, 


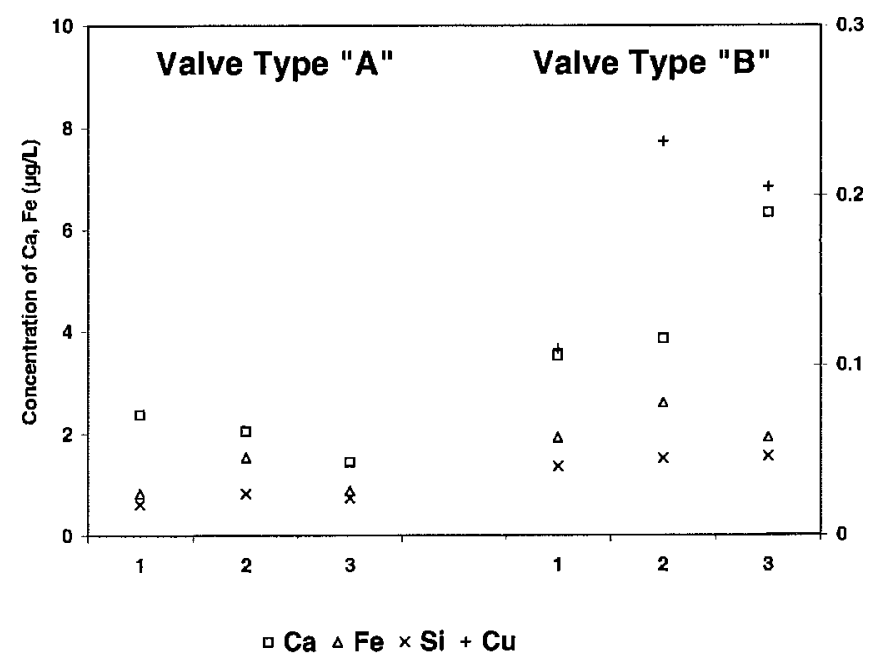

Fig. 7 Leaching test of two types of PVDF valves. Three valves of each type were leached for seven days. Cu was below the detection limit of $0.08 \mu \mathrm{g} / \mathrm{L}$ in all samples of type " $\mathrm{A}$ "

and for $\mathrm{Ag}$, the recovery was below $10 \%$ since it is one of the elements forming volatile fluorides during the ashing procedure. Another problem are memory effects. Figure 6 shows the result of a procedural blank sample in a crucible that had previously been used for a recovery experiment. Although the crucible had been cleaned according to the standard procedure, there were detectable traces of $\mathrm{La}, \mathrm{Nd}$, Dy and Lu, presumably from the multi-element spike used, W, present as impurity in most PVDF samples, and Ir, which comes from the Pt crucible material.

Leaching tests are used to determine the leachable fraction of impurities present in a component. Figure 7 shows a comparison between two types of PVDF-valves leached for seven days at $85^{\circ} \mathrm{C}$. It is obvious that type $A$ is "cleaner" than the type B valves since the concentrations of the elements detected are lower in the three type A samples. Figure 8 shows the concentrations of $\mathrm{Sr}$ and Ba found after 1, 7 and 28 days in a comparison between two types of polypropylene tubes. Practically no determinable concentrations were found in the leaches of the type A samples. The result of the six identical tubes from type B shows that the levels of leached impurities decrease with time and that the test is very reproducible. For $\mathrm{Sr}$, a relative standard deviation of only $14 \%$ was found between the six samples at an average concentration of $22 \mathrm{ng} / \mathrm{L}$ after 28 days' leaching.

\section{Authentication of antique silver alloys}

Silver antiques can be authenticated based on the levels of impurities of elements such as $\mathrm{Au}, \mathrm{Bi}, \mathrm{Cd}, \mathrm{Pb}, \mathrm{Sb}, \mathrm{Sn}$ and $\mathrm{Zn}[22,23]$. One of the most important goals is to perform an analysis that is practically non-destructive. The determination of the relevant elements by ICP-MS can be carried out after dissolving the sample in nitric and hydrochloric acid. This method has two disadvantages: the relatively high sample consumption, typically around $5 \mathrm{mg}$,
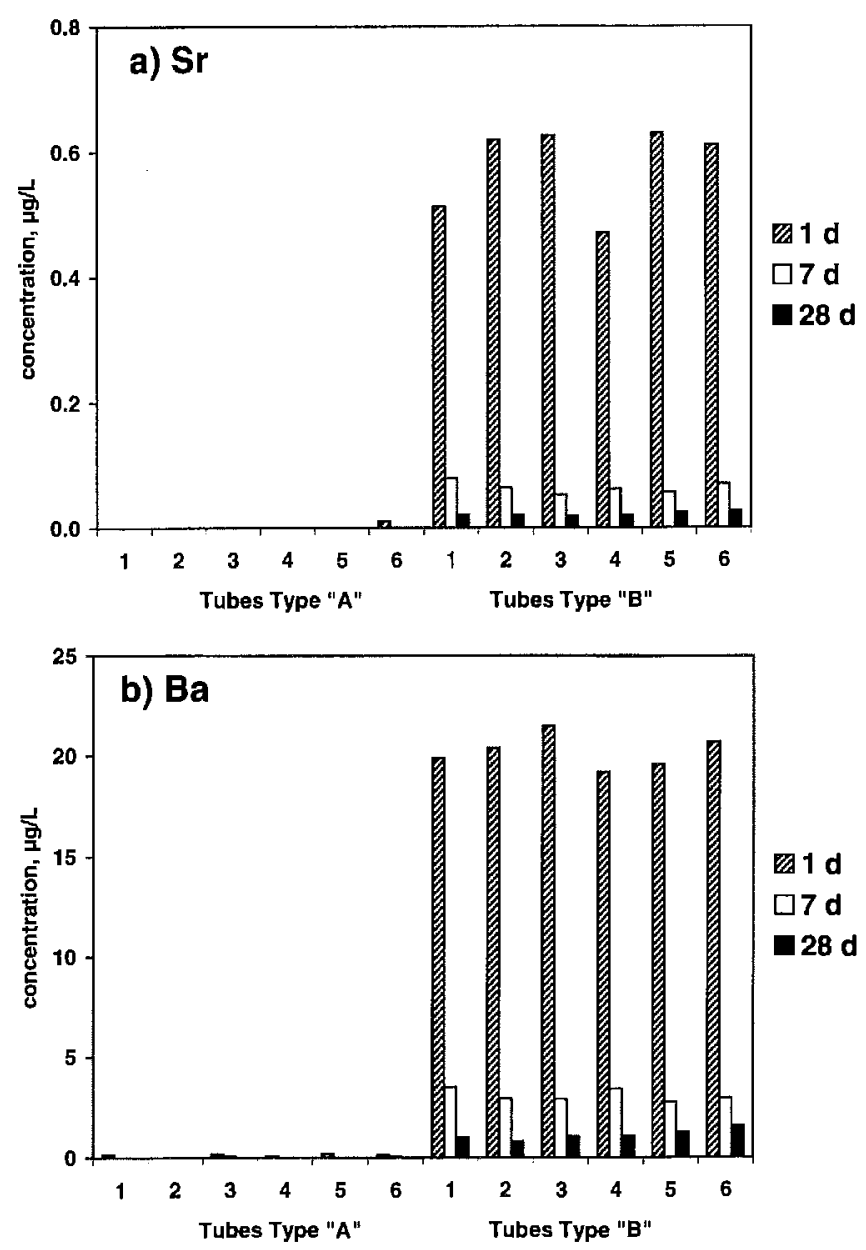

Fig. 8 Leaching test of two types of PP tubes. $a$ ) results for $\mathrm{Sr}, b$ ) results for $\mathrm{Ba}$. Six tubes of each type were leached for 1,7 and 28 days, with a complete change of water after each sampling

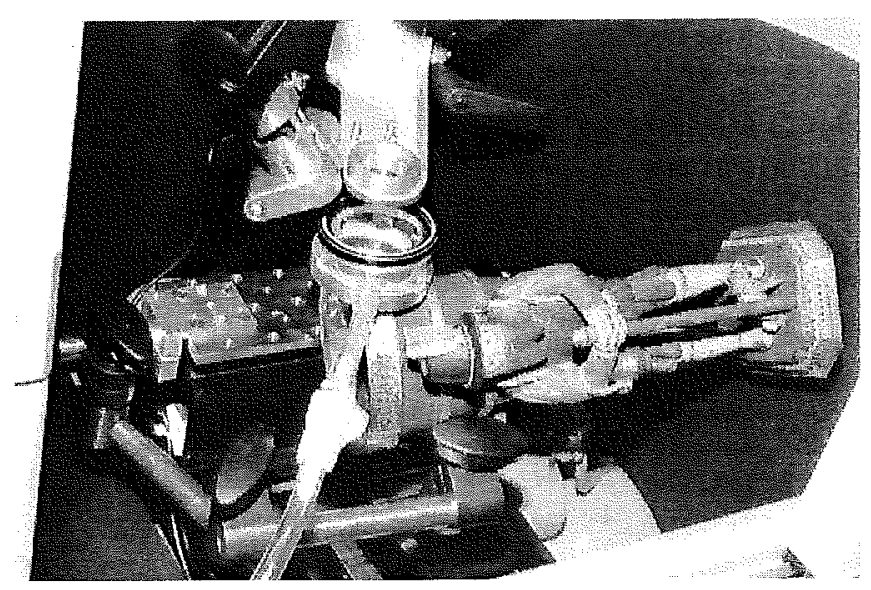

Fig.9 Laser ablation of antiques: the modified sample cell allows the direct ablation of large objects; an autofocus system guarantees the reproducible positioning of the sample surface in the focal plane of the laser beam

and the precipitation of Ag as silver chloride after the addition of hydrochloric acid. These drawbacks can be overcome by solid sampling in combination with graphite fur- 

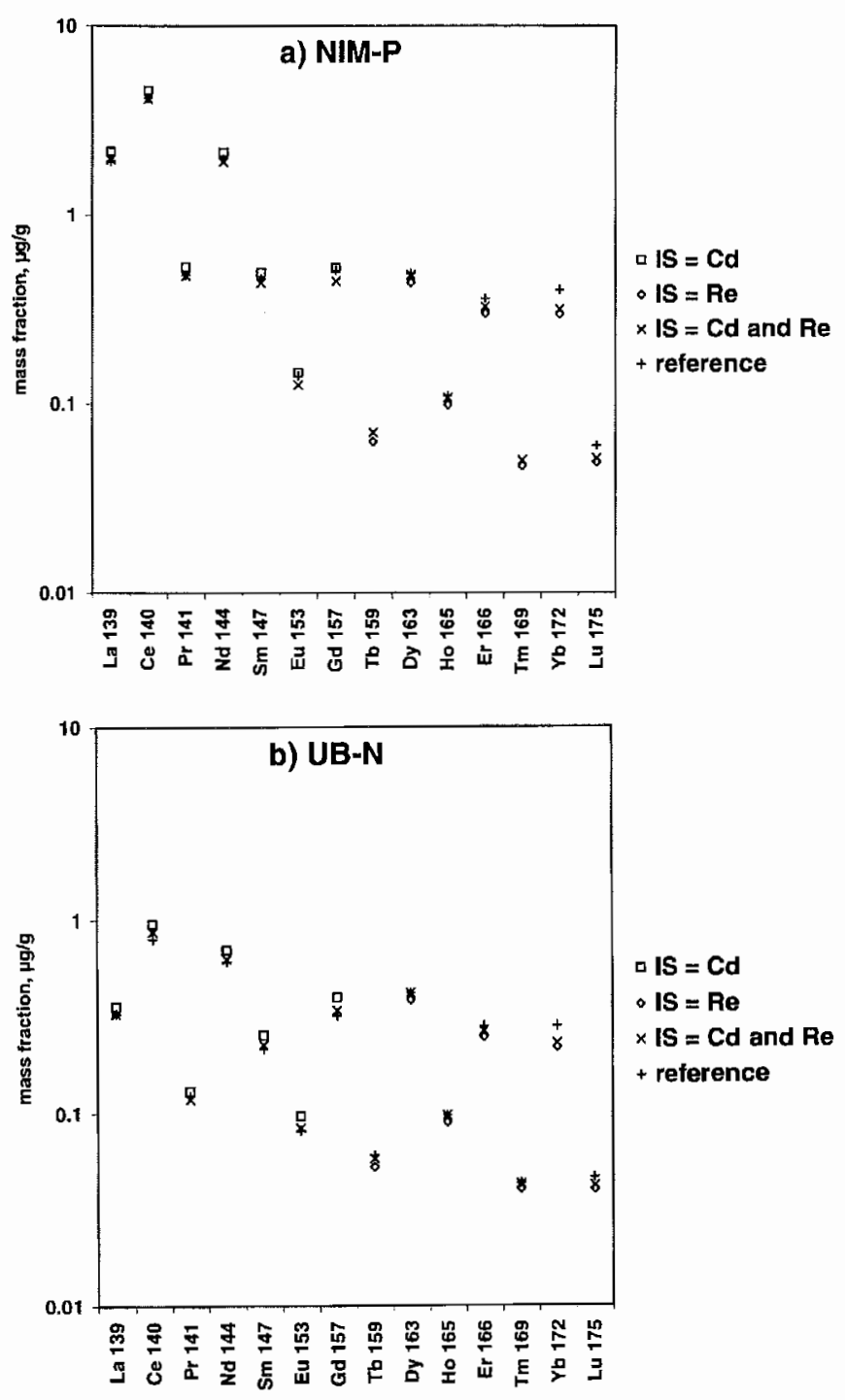

Fig. 10 Rare earth elements in two geological reference materials a) NIM-P and $b$ ) UB-N with different methods of internal standardization. "IS $=\mathrm{Cd}$ " $(\mathrm{Re})$ means that $\mathrm{Cd}$ (or Re) only was used as internal standard; "IS = Cd and Re" stands for results obtained using the calculated correction factor. No reference data are available for $\mathrm{Tb}$ and $\mathrm{Tm}$ in NIM-P

nace AAS for single element determinations [24] or ETVICP-MS for multi-element determinations [7], performing a micro-digestion in the graphite tube by nitric acid only. Reasonably linear calibration curves (e. g. for Au, 4 calibration points, $R=0.996$ ) were obtained with solid standard samples and $\mathrm{Ag}$ as an internal standard [7]. However, this method was rather slow and the total sample consumption was still about $1 \mathrm{mg}$, since not all chips shaved from the object had the right size to be inserted into the graphite tube through the access hole.

After some modifications of the original equipment, laser ablation ICP-MS was found to be ideal in minimizing the damage to the object (Fig. 9). A set of three commercial reference materials was used for calibration, and a good linearity, with correlation coefficients usually above
0.999 , was obtained [3]. The calibrated range from 10 to $500 \mu \mathrm{g} / \mathrm{g}$ appears high for ICP-MS, but it covers the concentration range of typical impurities in antique alloys. It has to be emphasized that the requirement was to minimize the damage to the object by using the high sensitivity of ICP-MS to analyze a small amount of the sample, not to reach the lowest possible detection limits.

Determination of rare earth elements in geological materials

ICP-MS has become the method of choice for the determination of lanthanides in geological materials [25-30]. We regularly have to determine rare earth elements in geological samples in series of 50 to 150 samples that have been digested at the Institute of Mineralography and Petrography (ETH Zurich). In this case, an external calibration with two internal standards was applied for quantification: $\mathrm{Cd}$ for the elements from $\mathrm{La}$ to $\mathrm{Gd}$, and $\mathrm{Re}$ for the elements from $\mathrm{Tb}$ to $\mathrm{Lu}$. The results obtained with that calculation showed that there was a mass-dependent systematic error compared to literature values (Fig. 10) [31, 32], which could be explained by the effect of the internal standardization. Since the internal standard should match the analyte mass (and the ionization energy) as closely as possible, a correction factor based on the intensity change of both standards could be calculated by weighing the influence of both internal standards according to the mass difference to the analyte:

$c(X)=c(X, C d) \times(m / b)+c(X, R e) \times(b-m) / b$

where $c(X)$ is the mass fraction of the analyte $X, c(X, C d)$ and $c(X, R e)$ the mass fraction of $X$ calculated with the corresponding internal standard, $\mathrm{m}$ the mass difference between ${ }^{185} \mathrm{Re}$ and the measured isotope, and $\mathrm{b}$ is 74 , i. e. the mass difference between ${ }^{185} \mathrm{Re}$ and ${ }^{111} \mathrm{Cd}$. Figure 10 shows that with the application of two internal standards, all values are close to the literature values.

\section{Conclusion}

These four examples demonstrate typical challenges for ICP-MS. The identification of lead bullets was achieved with a semi-quantitative determination of thirty elements and with an isotope ratio determination. The determination of impurities in polymers for ultra-pure water distribution systems was carried out either by digestion or by leaching procedures at the $\mathrm{ng} / \mathrm{g}$ level for solids or $\mathrm{ng} / \mathrm{L}$ for liquid samples. For this kind of analysis, the main problem is not the instrument sensitivity but a rigorous contamination control. Analyzing antique silver alloys, the high sensitivity of the technique was not used for measuring very low concentrations, but for minimizing the absolute sample consumption utilizing sample introduction systems for solids. The example of determination of rare earth elements in geological samples shows that even a result that is satisfactory at first glance can be improved if 
the basic concepts of ICP-MS are carefully applied. It is obvious that in a complex matrix we need accurate and precise determinations using robust calibration strategies such as isotope dilution or standard additions. In the example discussed, an optimized internal standardization in combination with external calibration was appropriate to solve the current problem.

In addition to these applications from our laboratory, a variety of different tasks can be performed with modern instruments due to the inherent features of the technique [33]. The high sensitivity is a prerequisite for the analysis of chemical reagents for the semiconductor industry [20, $34]$ and for environmental analysis $[35,36]$. Both the sensitivity and the short measuring time in order to record transient signals are the fundamentals for the coupling of ICP-MS with laser ablation [37] (for local analysis in geological and material sciences) and with chromatography [38] or capillary electrophoresis [39] (for speciation analysis in biological, medical and environmental studies). Important developments in the last few years have enhanced the versatility of the technique. Spectral interferences are drastically reduced using a double-focusing sector field MS [40] or by a reaction cell as an interface to a quadrupole MS [41, 42]. Shorter measurement times are obtained with a time-of-flight MS [43]. Simultaneous signal registration can also be reached by using a multi-collector instrument [44] and will improve isotope ratio analysis and isotope dilution-ICP-MS [45].

However, modern instrumentation is just a part of the story. High demands are made also on the analysts and technicians. In order to work efficiently and successfully, they should always keep in mind the primary goal of the current investigation: to solve the problem of their client. The analyst planning the protocol in the laboratory has to be aware of the capabilities of the instruments available, and to know how they can be operated in order to reach a given goal. As a consequence, he will then be able to choose a method suited to the current problem, rather than adapt the problem to a method that is easily available.

\section{References}

1. Richner P, Evans D (1993) At Spectrosc 14: 157-161

2. Wanner B, Moor Ch, Richner P, Brönnimann R, Magyar B (1999) Spectrochim Acta 54B: 287-296

3. Devos W, Moor Ch, Lienemann P (1999) J Anal At Spectrom 14: $621-626$

4. Provisional Test Method for Determining Bulk Trace Metals in Polymer Materials of UPW Distribution System Components, 92010938B-STD (1992) SEMATECH Technology Transfer, Austin

5.Provisional Test Method for Sample Preparation for Chemical Testing of UPW Distribution System Components, 92010934BSTD (1992) SEMATECH Technology Transfer, Austin

6. Tanner SD, Paul M, Beres SA, Denoyer ER (1995) At Spectrose 16: 16-18

7. Moor Ch, Boll P, Wiget S (1997) Fresenius J Anal Chem 359: $404-406$

8. Tuchschmid M (1993) Thesis No 9954, ETH Zurich

9. Suzuki Y, Marumo Y (1996) Anal Sci 12: 129-132

10. Dufosse T, Touron P (1998) Forensic Sci Int 91: 197-206
11. Watling RJ, Herbert HK, Delev G, Abell ID (1994) Spectrochim Acta 49B: 205-219

12. Watling RJ, Lynch BF, Herring D (1997) J Anal At Spectrom 12: 195-203

13. Graney JR, Halliday AN, Keeler GJ, Nriagu JO, Robbins JA, Norton SA (1995) Geochim Cosmochim Acta 59: 1715-1728

14. Croudace IW, Cundy AB (1995) Environ Sci Technol 29: $1288-1296$

15. Moor Ch, Schaller 'T, Sturm, M (1996) Environ Sci Technol 30: 2928-2933

16. Camarero L, Masqué P, Devos W, Ani-Ragolta I, Catalan J, Moor Ch, Pla S, Sanchez-Cabeza JA (1998) Water Air Soil Poll 105: 439-449

17. Chaudary-Webb M, Paschal DC, Elliott WC, Hopkins HP, Ghazi AM, Ting BC, Romieu I (1998) At Spectrosc 19: 156163

18. Gale NH, Stos-Gale ZA (1992) In: Pollard AM (ed) New Developments in Archaeological Science, Proc Brit Acad 77, Ox ford University Press Oxford, pp 63-108

19. Ghazi MA (1994) Appl Geochem 9: 627-636

20. Balazs MK (1995) R\&D Magazine, June, 51-56

21. Takeda K, Watanabe S, Naka H, Okuzaki J, Fujimoto T (1998) Anal Chim Acta 377: 47-52

22. Richter E-L (1983) Altes Silber: imitiert-kopiert-gefälscht. Keyser, Munich

23. Mushlitz RD (1994) In: McGraw-Hill Multimedia Encyclopedia of Science and Technology-'Silver Metallurgy', McGrawHill, New York, CD-ROM Version 1.0

24. Hinds MW (1993) Spectrochim Acta 48B: 435-445

25. Jarvis KE (1988) Chem Geol 58: 31-39

26. Ochsenkuhn-Petropoulou M, Ochsenkuhn K, Luck J (1991) Spectrochim Acta 46B: 51-65

27. Marabini AM, Passariello B, Barbaro M (1992) Mater Chem Phys 31: 101-106

28. Shinotsuka K, Hidaka H, Ebihara M, Nakahara H (1996) Anal Sci 12: 917-922

29. Itoh A, Hamanaka T, Rong W, Ideka $K$, Sawatari $H$, Chiba K, Haraguchi H (1999) Anal Sci 15: 17-22

30. Yan X-P, Kerrich R, Hendry MJ (1999) J Anal At Spectrom 14: $215-221$

31. Ionov DA, Savoyant L, Dupuy C (1992) Geostand Newsl 16: 311-315

32. Müntener O (1997) Thesis No 12103, ETH Zurich

33. Taylor HE, Huff RA, Montaser A (1998) In: Montaser A (ed) Inductively Coupled Plasma Mass Spectrometry, Wiley-VCH, New York, pp 681-807

34. Laly S, Nakagawa K, Kimijima T (1996) Fresenius J Anal Chem 356: 31-36

35. Willic SN, Iida Y, McLaren JW (1998) At Spectrosc 19: 67-72

36. Warnken KW, Gill GA, Wen LS, Griffin LL, Santschi PH (1999) J Anal At Spectrom 14: 247-252

37. Günther D, Jackson SE, Longerich HP (1999) Spectrochim Acta 54B: 381-409

38. Cairns WRL, Ehdon L, Hill SJ (1996) Fresenius J Anal Chem 355: 202-208

39. Van Holderbeke M, Zhao Y, Vanhaecke F, Moens L, Dams R, Sandra P (1999) J Anal At Spectrom 14: 229-234

40. Jakubowski N, Moens L, Vanhaecke F (1998) Spectrochim Acta 53B: $1739-1763$

41. Turner PJ, Meren T, Speakman J, Haines C (1997) In: Holland G, Tanner SD (eds) Plasma Source Mass Spectrometry: Developments and Applications, Royal Soc Chem, Cambridge, pp 28-34

42. Tanner SD, Baranov VI (1999) At Spectrosc 20: 45-52

43. Myers DP, Li G, Mahoney PP, Hieftje GM (1995) J Am Soc Mass Spectrom 6: 411-420

44. Walder AJ (1997) In: Platzner IT (ed) Modern Isotope Ratio Mass Spectrometry, Chem Anal Vol 145, Wiley, Chichester, pp 83-108

45. Heumann KG, Gallus SM, Vogl J (1998) J Anal At Spectrom 13: $1001-1008$ 
